\title{
Foraging ecology of a marine top predator in the Eastern Tropical Pacific over 3 years with different ENSO phases
}

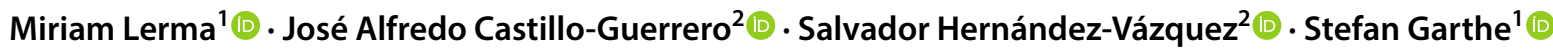

Received: 15 October 2019 / Accepted: 28 April 2020 / Published online: 3 June 2020

(c) The Author(s) 2020

\begin{abstract}
The El Niño Southern Oscillation (ENSO) is a recurrent climatic pattern with important ecological consequences for seabirds due to its impacts on the abundance and distribution of food resources. We investigated the effects of ENSO phases on the foraging ecology of a marine top predator at Clarion Island in the Eastern Tropical Pacific using GPS and time-depth recorder data and regurgitates from incubating masked boobies (Sula dactylatra) during 3 consecutive years. Foraging locations were recorded in 2016 (El Niño, one female, three males), 2017 (neutral; six females, nine males), and 2018 (La Niña; eight females, ten males). Local sea surface temperature (SST) and chlorophyll-a concentration (CHL) within the birds' foraging range were compared among the 3 years. Regurgitates were collected opportunistically from 25 and 31 incubating adults in 2017 and 2018, respectively. Average local CHL and SST were similar among years (mean SST $25^{\circ} \mathrm{C}$; mean CHL 0.10 and of $0.09 \mathrm{mg} \mathrm{m}^{-3}$ in January and March, respectively). Masked boobies travelled a maximum of $66 \pm 34 \mathrm{~km}$ from the colony. The maximum trip duration was $7.7 \pm 3.4 \mathrm{~h}$ and total distance travelled during a foraging trip was $164 \pm 73 \mathrm{~km}$, with no sexor year-related differences. Masked boobies mainly caught flying fish, but their diet also included one squid and six other fish families. In contrast to previously reported changes in foraging ecology of seabirds, masked boobies at Clarion Island seemed to be unaffected during El Niño, because the local oceanography was relatively unperturbed by ENSO oscillations.
\end{abstract}

\section{Introduction}

The El Niño-Southern Oscillation (ENSO) is a dominant driver of inter-annual variabilities in the physical and biogeochemical states in the Pacific. Its warm phase, El Niño, is perhaps the most important climatic anomaly in the Eastern Tropical Pacific (McPhaden et al. 2006; DiLorenzo and Miller 2017), causing wide-scale ecological disturbances

Responsible Editor: V. Paiva.

Reviewed by undisclosed experts.

Electronic supplementary material The online version of this article (https://doi.org/10.1007/s00227-020-03699-6) contains supplementary material, which is available to authorized users.

Miriam Lerma

lerma@ftz-west.uni-kiel.de

1 Research and Technology Center (FTZ), University of Kiel, Hafentörn 1, 25761 Büsum, Germany

2 Centro Universitario de la Costa Sur, Universidad de Guadalajara, Gómez Farías 82, CP 48980 Melaque, Jalisco, Mexico in the region (DiLorenzo and Miller 2017). The intensity and frequency of El Niño events are currently increasing as a result of human-accelerated climate change (Walther et al. 2002; Cai et al. 2014) and are unlikely to be accounted for solely by natural variability (Trenberth and Hoar 1997). Increases in the frequency of El Niño events are predicted to lead to decreased ocean productivity, altered food web dynamics, and shifts in species distributions (Walther et al. 2002; Hoegh-Guldberg and Bruno 2010; DiLorenzo and Miller 2017). Changes in the availability and distribution of fish species may impact the prey availability for top predators like seabirds, with consequences for their behavior, physiology, and demography (Vargas et al. 2006; Grémillet and Boulinier 2009; Oro 2014; Champagnon et al. 2018). Seabirds are currently the most threatened group of birds (Croxall et al. 2012) and conservation actions that anticipate the effects of climate change on their populations are required (Monahan and Fisichelli 2014). However, predicting the effects of global warming on seabirds is complicated by gaps in knowledge for many remote tropical regions (Oro 2014), and there is thus a need for local studies to obtain information on the reactions of seabird species to local and 
wide-scale environmental oscillations (Jenouvrier 2013; Oro 2014).

Seabirds may respond to changes in the availability of their main prey by switching the targeted prey species (Ancona et al. 2012) and adjusting their foraging behavior (Harding et al. 2007; Elliott et al. 2008; Castillo-Guerrero et al. 2016). During periods of lower productivity, which affect prey abundance, seabirds may forage further and for longer periods (Burger and Piatt 1990; Harding et al. 2007) and switch prey species and size (Burger and Piatt 1990; Croxall et al. 1999). Seabird species differ in terms of their behavioral plasticity (Gilmour et al. 2018), and although relatively plastic species continue to breed during El Niño events, less-plastic species may experience dramatic population collapses (Ribic et al. 1997; Quillfeldt and Masello 2013; DiLorenzo and Miller 2017; Wingfield et al. 2018). Masked boobies (Sula dactylatra) represent an ideal species for documenting the effects of El Niño events in a tropical marine predator. This species is large enough to carry tracking devices, continues breeding even during El Niño events (Nelson 1978), and individuals may adjust their foraging movements and prey items according to availability (Nelson 1978; Sommerfeld et al. 2015).

Notably, masked boobies are sexually sized dimorphic, with females being $16 \%$ heavier and $2 \%$ larger than males (Sommerfeld et al. 2013). Some seabird species with size dimorphism have shown sex-specific foraging strategies during periods of reduced food availability (Ishikawa and Watanuki 2002). However, previous studies of masked boobies found no evidence of sex differences in foraging parameters (Weimerskirch et al. 2009; Young et al. 2010; Kappes et al. 2011; Oppel et al. 2015; Poli et al. 2017), though males in some colonies had lower diving rates and dived less deeply than females (Sommerfeld et al. 2013; Weimerskirch et al. 2009). Foraging segregation between sexes may occur only under specific circumstances, e.g. when environmental conditions are poor and food becomes scarce (Castillo-Guerrero and Mellink 2011; Paiva et al. 2017; Miller et al. 2018). It is therefore important to explore the influence of climate on the foraging ecology of both sexes in seabirds, to highlight demographic heterogeneities with potential consequences for population dynamics (Oro et al. 2010, 2018; Patrick and Weimerskirch 2014).

In this study, we obtained tracking and diving data and collected and analyzed diet samples from masked boobies to describe the foraging ecology of this species under different environmental regimes (in relation to ENSO phases), and to evaluate the influence of wide-scale environmental conditions on local oceanography and foraging segregation between the sexes. We hypothesized that masked boobies would forage further and for longer periods during periods of lower productivity (which affect prey abundance), and may switch prey species and size. We also considered that sexual segregation in foraging would occur during periods of lower productivity (e.g. during El Niño), whereas foraging differences between sexes would be less evident during periods of average or high productivity (e.g. neutral or La Niña years).

\section{Materials and methods}

\section{Data collection}

Revillagigedo Archipelago is a Mexican-designated marine protected area in the Eastern Tropical Pacific Ocean (CONANP 2017; DOF 2017) and is within an area vulnerable to marine heatwaves (Frölicher and Laufkötter 2018; Smale et al. 2019). Clarion Island is the most remote island of the archipelago, with breeding populations of several species of birds, including the ground-nesting, piscivorous masked booby (S. dactylatra). Clarion Island ( $18^{\circ} 21^{\prime} 7.53^{\prime \prime}$ $\mathrm{N}, 114^{\circ} 43^{\prime} 18.61^{\prime \prime} \mathrm{W}$; Fig. 1), which lies $985 \mathrm{~km}$ west of the Mexican mainland and $710 \mathrm{~km}$ southwest of the Baja California peninsula (Wanless et al. 2009), includes a breeding colony of around 100 pairs of masked boobies (Wanless et al. 2009; Almanza-Rodríguez 2019).

We visited Clarion Island for 30-day periods in January 2016, March 2017, and March 2018, respectively. Tracking data were collected opportunistically from incubating birds using i-gotU Loggers (i-gotU GT-120: Mobile Action, Taiwan) in 2016 (four females and four males), and CatLog-S Loggers (Catnip Technologies, Hong Kong, China) in 2017 (six females and nine males) and 2018 (eight females and ten males) (Supplementary material 1). Incomplete trips (departure or return from/to the nest not registered) and gaps in the tracking data while at sea occurred in 2016 (1-82 min), 2017 (1-13 $\mathrm{min})$, and 2018 (1-8 $\mathrm{min})$ due to battery failure of the

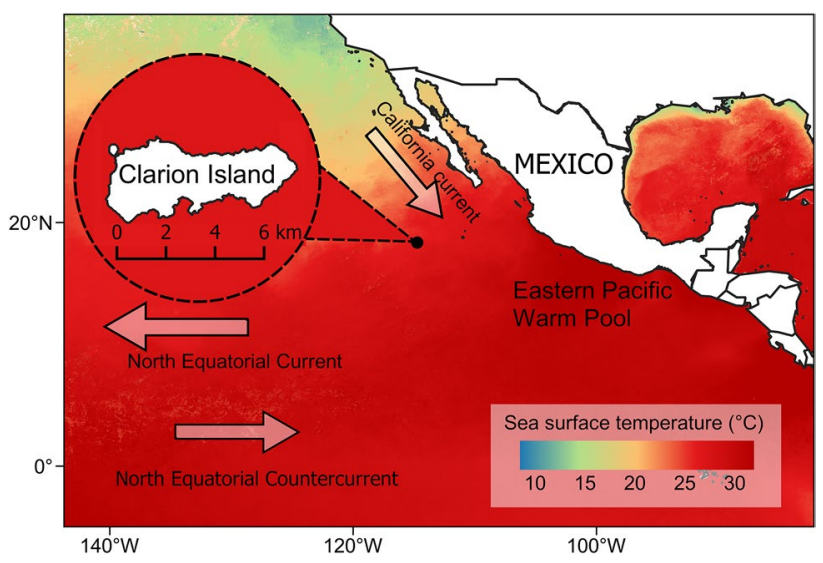

Fig. 1 Location of Clarion Island in the Eastern Pacific Ocean. Schematic representation of currents. Background shading indicates sea surface temperature in January 2016 
GPS devices. Incomplete trips were excluded from the analyses, and trips with gaps were included to estimate foraging trip parameters. After data selection, 10 trips from four individuals in 2016, 47 trips from 15 individuals in 2017, and 58 trips from 18 individuals in 2018 were included in the analyses (Supplementary material 1). The GPS devices were programmed to record time, latitude, and longitude every $1 \mathrm{~min}$ in 2016 and $4 \mathrm{~min}$ in 2017 and 2018. Twentyone of the birds with GPS devices were also equipped with time-depth recorders (TDRs; model G5+, Cefas Technology, UK), but only six birds had identifiable dives in 2017 and one in 2018. The TDR devices were programmed to record pressure data every $1 \mathrm{~s}$ on 12 bits.

Individuals were captured at their nest by hand or using a hand net from a distance of $1 \mathrm{~m}$. The sex of the individuals was determined by size and vocalization; females are bigger and have a rough voice, whereas males are smaller and have a high-pitched voice (Nelson 1978). The devices were attached using TESA tape on top of the three central tail feathers. The GPS devices, including the waterproof heat-shrink casing, weighed 22-30 g and the TDR devices weighed $6.5 \mathrm{~g}$. The masked boobies weighed $1.4-2.6 \mathrm{~kg}$ and the combined devices, therefore, did not exceed the recommended 3\% weight threshold for attached devices (Wilson and McMahon 2006; Vandenabeele et al. 2012). The total handling time never exceeded $10 \mathrm{~min}$ to minimize distress to the birds as a result of the tagging process. Individuals were captured at night from 19:00 to 03:00 h to prevent sunstroke to the birds and to avoid potential predation of eggs and chicks by common ravens (Corvus corax) and snakes (Masticophis anthonyi). Among the 37 tracked individuals, 16 lost their eggs during the tracking period. However, the loss of eggs was not exclusive to tagged individuals: from 62 nests monitored in 2017, 14 eggs hatched and 12 of the 14 chicks died (Almanza-Rodriguez 2019).

Diet samples were collected opportunistically in 2017 and 2018 if the bird regurgitated spontaneously as a result of our presence in the colony or during tagging. The whole regurgitate was placed in an individual plastic bag and weighed, and each prey item was later removed from the bag, photographed, and identified to the family level, based on Pacific fish guides (Fischer et al. 1995). Diet was described based on 'numerical frequency', defined as the number of items from a given prey family in relation to the total number of prey items (Alonso et al. 2018).

Environmental data on chlorophyll-a concentration (CHL) and sea surface temperature (SST) were downloaded from Aqua MODIS, NPP, 0.025 degrees, Pacific Ocean Lon \pm 180 , monthly composites, from the ERDDAP database (https://coastwatch.pfeg.noaa.gov/erddap). CHL and SST are influenced by ENSO (DiLorenzo and Miller 2017) and are considered to be good proxies for seabirds' prey availability (Kappes et al. 2010; Paiva et al.
2010). A circle of radius $180 \mathrm{~km}$ (maximum range of a masked booby from Clarion Island with an error threshold) was created around Clarion Island and the CHL and SST within the circle were extracted using the function 'extract' in the package 'raster' (Hijmans 2019). Using the extracted data for CHL and SST, we calculated the mean and standard deviation for each variable within the maximum foraging range for the breeding seasons in 2016, 2017, and 2018 (Figs. 2, 3). In addition, the Oceanic Niño Index (ONI) was used to classify the year as El Niño, La Niña, or neutral. ONI considers El Niño conditions to exist when the index is $\geq+0.5$ (indicating that the EastCentral Tropical Pacific is warmer than usual), La Niña when the index is $\leq-0.5$ (indicating that the region is colder than usual), and El Niño-neutral when the index is between -0.5 and +0.5 (https://www.cpc.ncep.noaa.gov/ products/analysis_monitoring/ensostuff/ensoyears.shtml).

\section{Data processing}

Tracking data were processed in $\mathrm{R}$ 3.6.2 ( $\mathrm{R}$ Core Team 2019). GPS fixes included multiple trips from a single bird. To obtain information on the foraging parameters per individual trip, all GPS fixes were analyzed using the function 'tripsplit' in the package 'IBA'. This function calculates the maximum distance from the colony, total distance travelled, and the trip duration for each individual trip (Lascelles et al. 2016). The maximum distance from the colony was measured as the most distant point in a straight line from the colony, total distance travelled was the summed distance between consecutive fixes from departure to return to the colony, and trip duration was the total time between departure and return to the colony. For the TDR data, a zero offset correction for surface drift was applied and only dives deeper than $0.5 \mathrm{~m}$ were considered as true dives.

For tracking data in 2017 and 2018, foraging behavior was determined based on the speed and turning angles from successive locations during the foraging trips using a clustering algorithm (Garriga et al. 2016). Value delimiters of $0.18-3.14$ (high turn) and $0-20 \mathrm{~km} \mathrm{~h}^{-1}$ (low speed) were used to identify foraging behavior and were within thresholds applied in other sulids (Mendez et al. 2017). Using the foraging locations, kernel estimation of the utilization distribution (UD) of core (50\%) and general (95\%) areas were delimited using the function 'kernelUD' in the package 'adehabitatHR' (Calenge 2006). The reference bandwidth was used (0.10-0.13), and the Bhattacharyya coefficient (BA) was calculated. BA is a measure of similarity between two probability distributions, indicating the overlap in kernel density estimates, and can range from 0 (no overlap) to 1 (identical UD). 
Fig. 2 Chlorophyll-a concentration $\left(\mathrm{CHL}, \mathrm{mg} \mathrm{m}^{-3}\right)$ in the Eastern Tropical Pacific (upper panels) and at Clarion Island (lower panels) in January 2016 (A1 and A2), March 2017 (B1 \& B2), and March 2018 (C1 \& C2). Black dot indicates study area; circle represents area used to extract mean and standard

Fig. 3 Sea surface temperature $\left(\mathrm{SST},{ }^{\circ} \mathrm{C}\right)$ in the Eastern Tropical Pacific (upper panels) and at Clarion Island (lower panels) in January 2016 (A1 \& A2), March 2017 (B1 \& B2), and March 2018 (C1 \& C2). Black dot indicates study area; circle represents area used to extract mean and standard deviation of SST deviation of $\mathrm{CHL}$
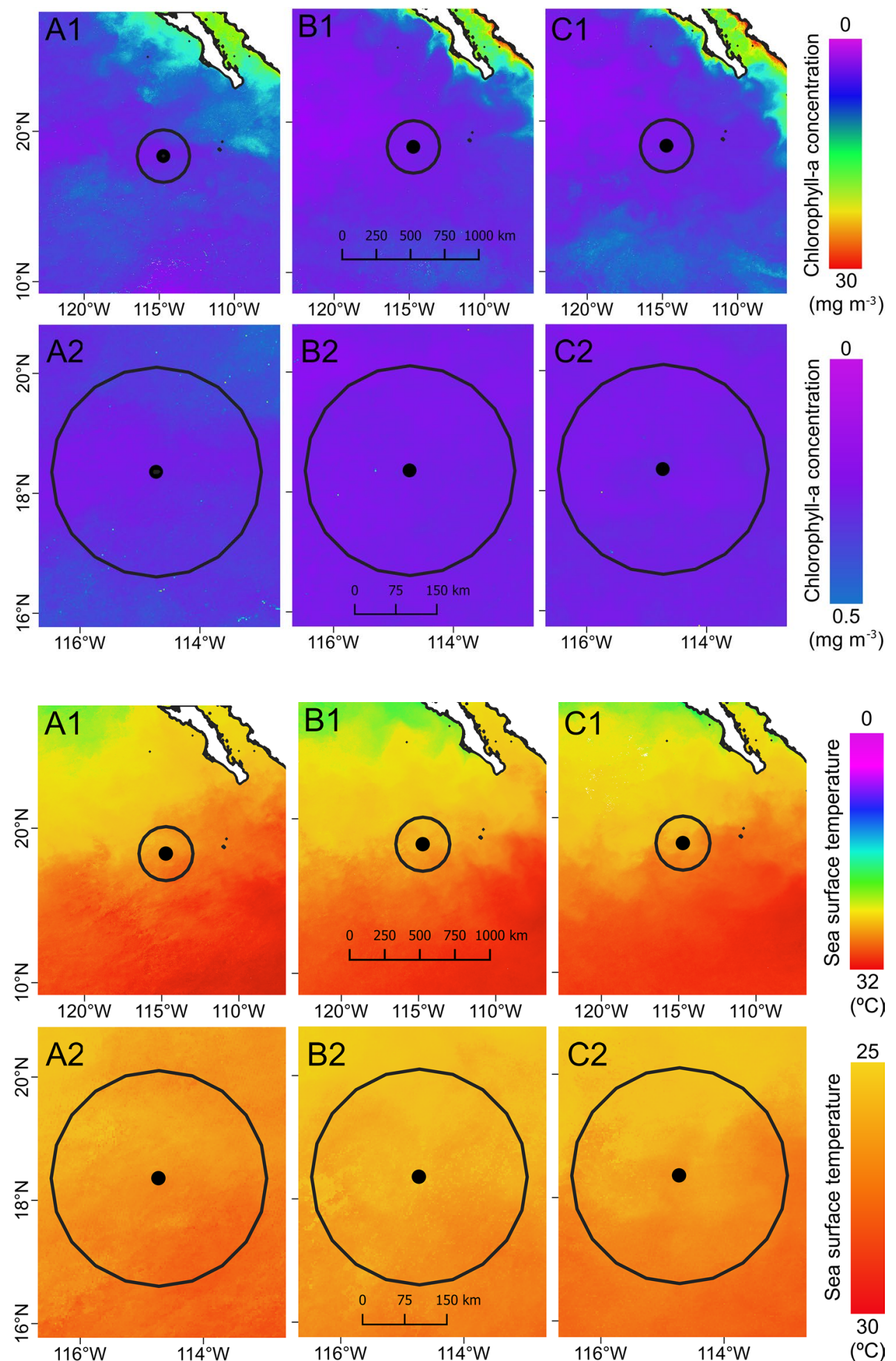

\section{Statistical analyses}

Inter-annual differences in CHL and SST were analyzed using one-way analysis of variance with year as factor. Differences in foraging parameters between sexes and years were analyzed using linear mixed-effect models in the package 'nlme' (Pinheiro et al. 2019) with maximum distance from the colony, total distance travelled, and trip duration as response variables, respectively. Residuals were plotted against fitted values and there was no obvious deviation from the assumption of normality and homoscedasticity of residuals. Year, incubation status (maintained and losing 
eggs), and sex were included as fixed factors, as well as the two-way interactions year $\times$ incubation status and year $\times$ sex. All models included individual bird identity as a random factor to avoid pseudo-replication. The significance of the factors was tested by comparing models with and without interactions and fixed factors. Comparisons were made using likelihood ratio tests (Kokubun et al. 2010; Peck-Richardson et al. 2018) using the 'anova' function.

The overlap between sexes and years (2017 and 2018) was calculated by analysis of similarity (ANOSIM) with BA on the 95\% and 50\% UD using the package 'vegan' (Oksanen 2019). We compared the number of prey items by year and sex, respectively, using chi-square tests. Statistics were performed in R 3.6.2 (R Core Team 2019) and maps were produced using QGIS 3.4 (QGIS Development Team 2019). The results are presented as mean \pm standard deviation.

\section{Results}

The environmental conditions within the foraging range of masked boobies $(<180 \mathrm{~km})$ during the 3-year study period (2016-2018) showed an average CHL concentration of $0.09 \pm 0.02 \mathrm{mg} \mathrm{m}^{-3}$ and average SST of $26.3 \pm 1.3{ }^{\circ} \mathrm{C}$. Average local CHL and SST did not differ significantly among years (CHL: ANOVA, $F(1,1)=2.12, P=0.38$, SST: ANOVA, $F(1,1)=0.61, P=0.58)$ (Figs. $2,3,4)$. Based on the ONI, January 2016 was an El Niño phase (ONI 2.5), March 2017 was El Niño-neutral (ONI 0.1), and March 2018 was a La Niña phase (ONI - 0.6) (Fig. 4). During the three tracking periods, the mean SST was $25^{\circ} \mathrm{C}$ and the mean CHLs were 0.10 and $0.09 \mathrm{mg} \mathrm{m}^{-3}$ during January and March, respectively. The conditions within the foraging range of the masked boobies thus remained stable and did not coincide with the expected ENSO conditions.

Tracked birds were observed during the tagging period of 4 days and no individual showed signs of discomfort associated with the devices, such as frequent touching the device or increased preening activities. We obtained 115 tracks from the 37 birds leaving the island to go to sea. There were no significant differences in foraging trip parameters among birds in relation to incubation status (maintaining or losing the egg), sex, or the three tracking periods (January 2016, March 2017, and March 2018) (Fig. 5) and there were no significant interactions between the factors (Table 1).

The areas used for foraging by masked boobies were similar between sexes and years (2017 and 2018) (BA range at 50\% UD: $0.11-0.99$, ANOSIM R $=-0.15, P=0.96$; BA range at 95\% UD: $0.10-0.99$, ANOSIM R $=-0.16, P=0.95$ ) (Fig. 6). Of the 18 diving devices deployed on individuals in 2017 and the three in 2018, only seven recorded identifiable dives, while the other devices had no clear dives or showed large pressure variations that prevented the identification of

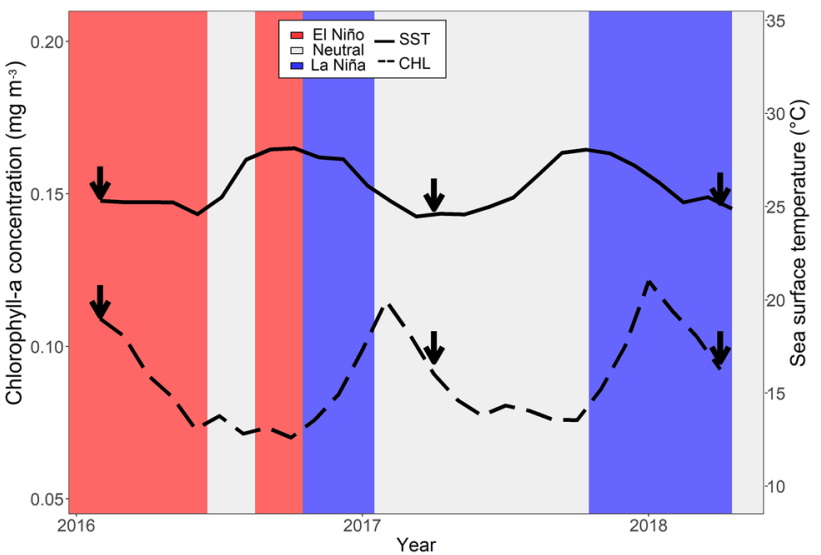

Fig. 4 Time series of monthly mean chlorophyll-a concentration (CHL, dashed) and sea surface temperature (SST, line) within the maximum foraging range $(180 \mathrm{~km})$ for masked boobies (Sula dactylatra) from January 2016 to April 2018. Background corresponds to the Oceanic Niño Index (ONI), which classifies conditions like El Niño (index $\geq+0.5$, indicating that the East-Central Tropical Pacific is warmer than usual), La Niña (index $\leq-0.5$, indicating that the region is colder than usual), and El Niño-neutral (index -0.5 to +0.5 ). Arrows indicate tracking periods in January 2016, March 2017, and March 2018

dives. Among all dives, $66 \%$ lasted $\leq 3 \mathrm{~s}$ and $82 \%$ were $\leq 2 \mathrm{~m}$ depth (Fig. 7). The deepest dive was $5.5 \mathrm{~m}$ and the longest $13 \mathrm{~s}$. No statistical comparisons of diving parameters were possible due to the limited number of recorded dives.

Regurgitates from 25 individuals in 2017 (14 females and 11 males) and from 31 individuals in 2018 (14 females and 17 males) were collected, comprising 186 individual prey items. The numerically dominant prey family for both female and male masked boobies in 2017 and 2018 was flying fish (Fig. 8). Regurgitates contained an average of $3.5 \pm 2.1$ prey items (range 1-13 items) from 1-3 families. The prey items in the diet were homogeneous between years (chi-square test, $X 7=4.96, P=0.66$ ) and sexes (chi-square test, $X 7=2.96, P=0.89$ ).

\section{Discussion}

Despite the limited number of samples, this study provides novel evidence for the foraging ecology of masked boobies at Clarion Island during consecutive years. We expected that masked boobies would show different foraging strategies in response to changes in the availability and distribution of their food resources; however, despite these assumptions, no significant ENSO effects were detected at Clarion Island.

Peaks in CHL and lower SST in the first trimester of the year mirrored the peaks from the California Current (LluchCota 2000; Valencia-Gasti et al. 2015) and demonstrated the influence of this current at Clarion Island. However, 
Fig. 5 Foraging trip parameters of masked boobies (Sula dactylatra) at Clarion Island during the breeding seasons in 2016 (birds $=4$, trips $=10$ ), 2017 (birds $=15$, trips $=47$ ), and 2018 $($ birds $=18$, trips $=58)$
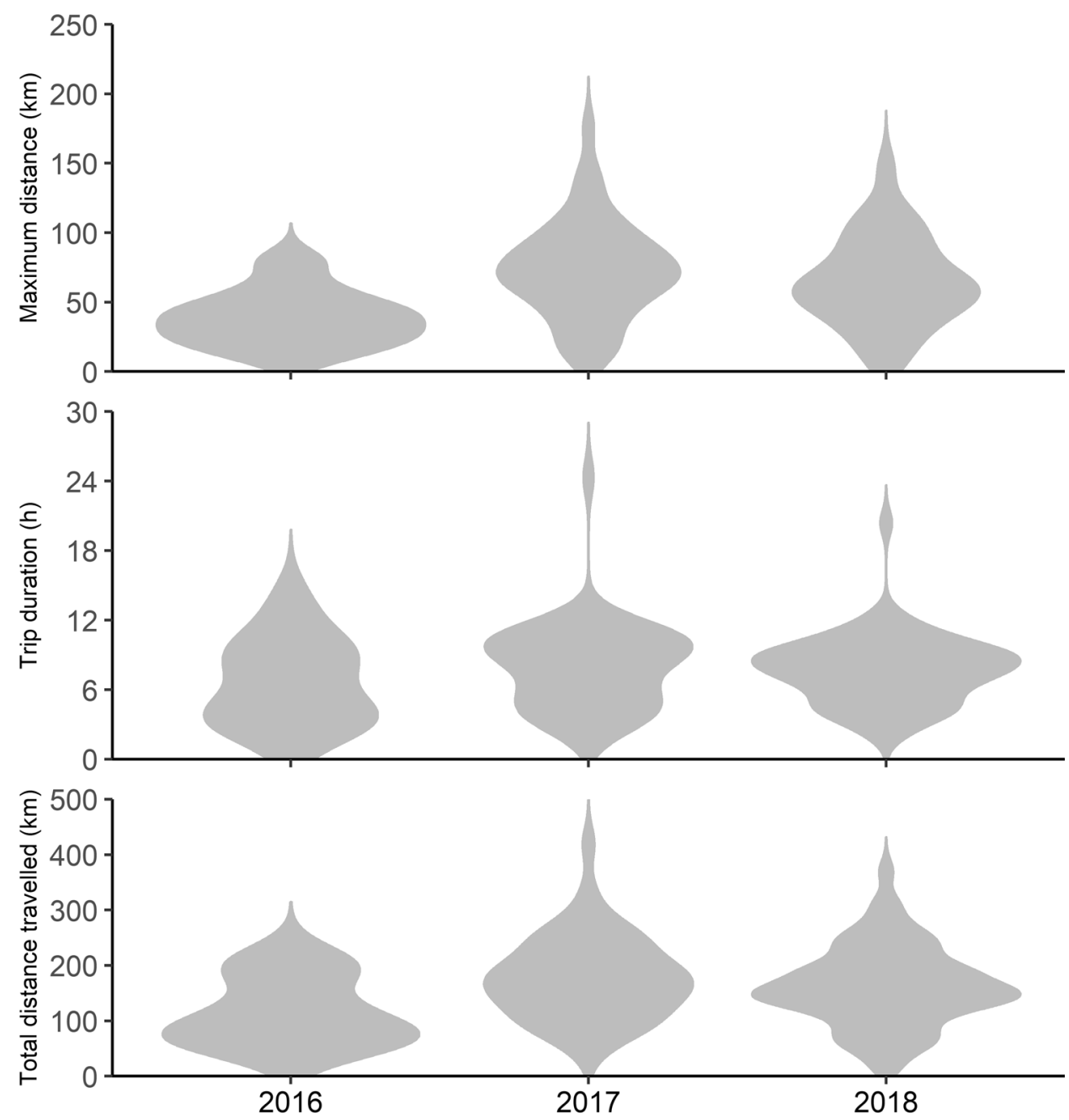

the CHL peaks in the coastal part of the California Current reached $1.8 \mathrm{mg} \mathrm{m}^{-3}$ (Lluch-Cota 2000), compared with a maximum of only $0.1 \mathrm{mg} \mathrm{m}^{-3}$ in the present study. The low influence of the California Current may be caused by the distance between Clarion Island and the coastal upwelling resulting in a weakened effect on productivity, such that the island maintains low-productivity waters that are less susceptible to ENSO-related environmental oscillations. The unusual environmental stability around Clarion Island, with no major inter-annual variations, may thus maintain stable local availability of the main prey species of masked boobies between ENSO phases, which may explain the consistent foraging parameters of masked boobies across years.

El Niño affects the abundance and distribution of fish species that depend on upwelling, such as anchovies and sardines (Velarde et al. 2004; Ancona et al. 2012; Quillfeldt and Masello 2013; Champagnon et al. 2018), and is thus especially challenging for seabirds adapted to prey on these small pelagic species. Nazca boobies (Sula granti) and blue-footed boobies (Sula nebouxii) in the Galapagos were reported to be affected by El Niño (Anderson 1989), probably because they depend on fish species such as anchovies, and sardines (Ancona et al. 2012; Tompkins et al. 2017). In contrast, red-footed boobies (Sula sula) and frigatebirds (Fregata minor), which prey on flying fish and squid (Schreiber and Hensley 1976; Young et al. 2010), remained unaffected during El Niño (Anderson 1989), suggesting that El Niño may not represent an additional pressure for seabird species in low-productivity warm waters, such as masked boobies, that prey on flying fish. This may also help to explain why seabirds inhabiting higher productivity areas are more severely affected by El Niño than those in low-productivity areas (Ribic et al. 1997; Quillfeldt and Masello 2013; DiLorenzo and Miller 2017). Masked boobies in the current study inhabited a low-productivity area and preyed mainly on flying fish and squid, which may show increased abundances in warm and low-productivity waters (Churnside et al. 2017; LluchBelda et al. 2014; Doubleday and Connell 2018).

Consistent with previous studies on masked boobies, we found no significant difference between females and males in terms of maximum distance from the colony, trip duration, or total distance travelled (Weimerskirch et al. 2009; Young 
Table 1 Effects of year (2016, 2017, and 2018), sex (female and male), incubation status (keeping or losing egg), and their interactions on foraging trip parameters in masked boobies (Sula dactylatra) at Clarion Island, based on linear mixed-effect models with the individual as a random factor

\begin{tabular}{lccl}
\hline & $\begin{array}{l}\text { Maximum } \\
\text { distance }\end{array}$ & Trip duration & $\begin{array}{l}\text { Total } \\
\text { distance } \\
\text { travelled }\end{array}$ \\
\hline Year & & & \\
$F_{1,4}$ & 0.49 & 0.04 & 0.32 \\
$P$ & 0.49 & 0.84 & 0.57 \\
Sex & & & \\
$F_{1,5}$ & 1.62 & 2.22 & 1.60 \\
$P$ & 0.20 & 0.14 & 0.21 \\
Incubation status & & \\
$F_{1,6}$ & 2.66 & $<0.01$ & 2.09 \\
$P$ & 0.10 & 0.97 & 0.15 \\
Sex $\times$ year & & & 0.26 \\
$F_{1,7}$ & 0.79 & 1.25 & 0.61 \\
$P$ & 0.37 & 0.26 & 1.27 \\
\multicolumn{2}{l}{ Year $\times$ incubation status } & & 0.26 \\
$F_{1,7}$ & 1.16 & 2.62 & \\
$P$ & 0.27 & 0.11 &
\end{tabular}

et al. 2010; Kappes et al. 2011; Oppel et al. 2015; Poli et al. 2017). Some previous studies found differences between the sexes in relation to diving depths and rates (Sommerfeld et al. 2013; Weimerskirch et al. 2009); however, although previous studies reported no problems with detecting and analyzing dives for masked boobies (Sommerfeld et al. 2015), our current devices failed to record enough diving events for statistical analysis. The failure of the devices to record the diving behavior of masked boobies could be because the birds were catching their prey on the wing, when subsurface predators flush flying fish or squid to the surface or out of the water (Davenport 1994; Muramatsu et al. 2013). Masked boobies are likely to catch prey on the wing because they form associations with tuna species during foraging ( $\mathrm{Au}$ and Pitman 1986), and albacore (Thunnus alalunga), yellow-fin (T. albacares), and bigeye (T. obesus) tuna, some of which also consume flying fish (Lacerda et al. 2017; Chagnon et al. 2018; Lewallen et al. 2018), all occur in the waters surrounding the Revillagigedo Archipelago. We recommend using accelerometers (Sommerfeld et al. 2013) or videography (Machovsky-Capuska et al. 2011) in future studies to investigate the diving behavior of masked boobies.

Foraging trip parameters from tracked birds that lost their eggs and remained to defend their territory/sit on their nest were similar to those for birds that kept their eggs. Losing eggs may influence the bird's behavior at sea because nonbreeding boobies move over larger distances than breeding boobies (Kohno et al. 2019). However, considering that masked boobies may lay second clutches within a period of 28-83 days (Priddel et al. 2005), tracked masked boobies that lost their eggs did not modify their foraging behavior because they may continue to be tied to the nest site. An alternative explanation is that non-breeding seabirds presumably disperse in response to changes in food availability and prevailing local conditions (Dingle and Drake 2007; Newton 2012), and there were no dramatic changes in the prevailing local conditions at Clarion Island. Thus, breeding and non-breeding birds may share foraging grounds yearround, due to the local environmental stability at Clarion Island.

It is necessary to apply caution when interpreting the current results, given that some sex-related foraging differences may have been overlooked. However, the present findings suggest that females and males from Clarion Island did not differ, at least in terms of the foraging parameters measured in the present study. Although there were some differences in prey species included in the diet between years and sexes, flying fish were consistently the main prey item for both sexes and in both years. Moreover, the maximum distance from the colony $(177 \mathrm{~km})$ travelled by masked boobies from Clarion Island was shorter than that travelled by masked
Fig. 6 Kernel density-based utilization distributions (UD) of foraging locations from masked boobies at Clarion Island by sex and year. Black dot indicates study area

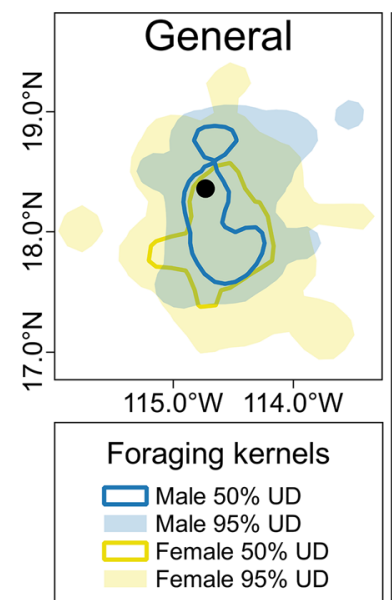

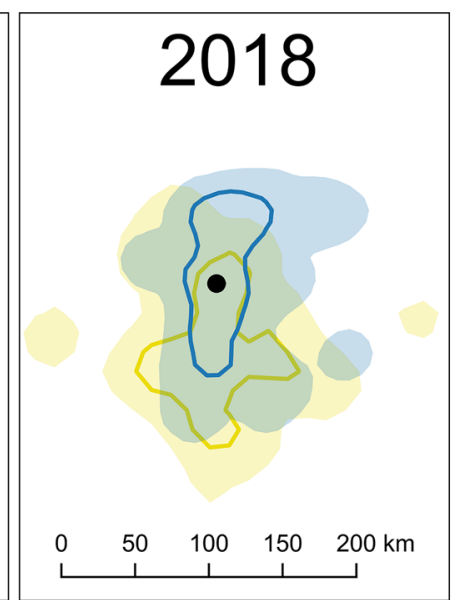



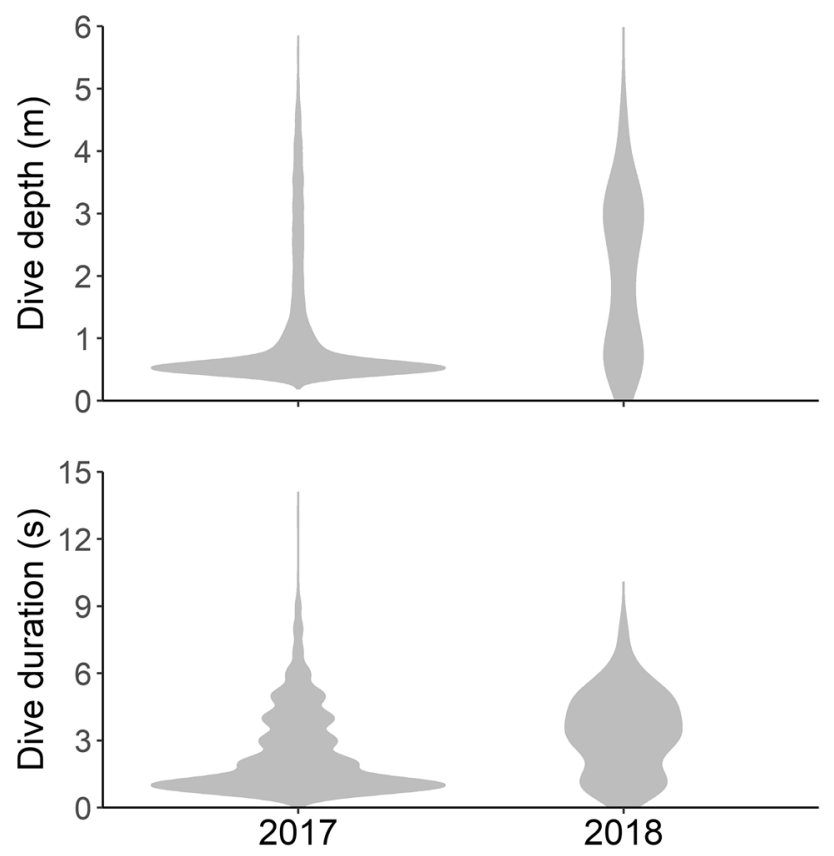

Fig. 7 Dive parameters of masked boobies (Sula dactylatra) at Clarion Island during the breeding seasons in 2017 (birds $=6$, dives $=1942)$ and $2018($ birds $=1$, dives $=62)$

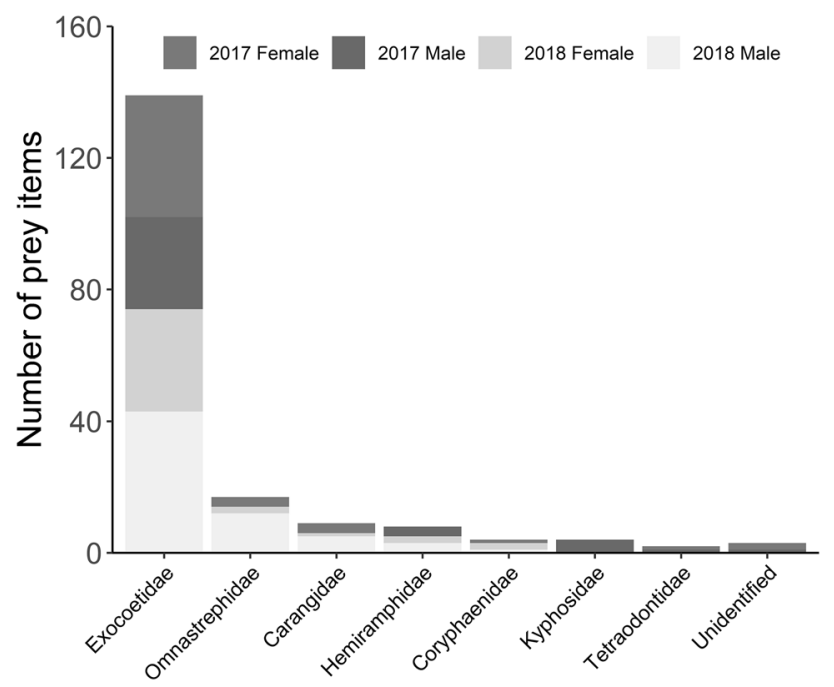

Fig. 8 Prey families in regurgitates from masked boobies (Sula dactylatra) collected at Clarion Island in 2017 (14 females, 11 males) and 2018 (14 females, 17 males). Families identified in the regurgitates included Exocoetidae (flying fish), Omnastrephidae (squid), Carangidae (jacks), Hemiramphidae (halfbeaks), Coryphaenidae (dolphinfish), Kyphosidae (sea chub), and Tetraodontidae (pufferfish)

boobies from Clipperton $(245 \mathrm{~km})$ (Weimerskirch et al. 2009), Phillip Island (231 km) (Sommerfeld et al. 2013), and Isla Muertos (232 km) (Poli et al. 2017). Masked boobies from less-densely populated colonies forage closer to the colony due to reduced intra-specific competition (Oppel et al. 2015). The small colony size (100 breeding pairs) and apparently stable prey availability at Clarion Island were thus associated with low levels of competition, and a consequent lack of sexual foraging segregation.

Although there were no clear effects of ENSO on the local oceanography and foraging behavior of masked boobies at Clarion Island, detailed information on foraging behavior taking account of dynamic oceanographic features such as currents and fronts (Cox et al. 2016; Poli et al. 2017; Spear et al. 2001), and with a larger sample size are needed. Moreover, the lack of response of masked boobies to El Niño does not mean that this seabird may not suffer from its consequences in other respects or at other colonies. Long-lived species such as masked boobies are expected to prioritize their own survival and future fecundity over individual breeding events (Drent and Dann 1980), and although El Niño may have no obvious effect in terms of their foraging behavior, it may have unseen impacts on their breeding participation or reproductive success (Dorward 1962; Priddel et al 2005). Brown boobies (Sula leucogaster) ceased breeding at Isla San Jorge (Mellink 2003) and experienced reproductive failure and adult mortality at Christmas Island (Schreiber and Schreiber 1989) in response to El Niño, whereas there was no evidence of any survival effects on brown boobies at Johnston Atoll (Beadell et al. 2003). Different effects on seabird behavior, physiology, and demography among colonies are likely to be related to the different local oceanographic conditions of the islands.

\section{Conclusions}

Contrary to our hypothesis, masked boobies did not travel further from their colony, or switch their prey items between sexes and years. The tropical pelagic ecosystem at Clarion Island remained environmentally stable, which may explain why the foraging ecology of masked boobies did not differ between years. The waters around Clarion Island did not follow the general ENSO-related patterns, showing that the general area around Clarion Island is less influenced by upwelling processes compared with coastal or other pelagic areas, where the effects are more dramatic. The similar foraging parameters of female and male masked boobies likely reflected low competition for food resources. We acknowledge that these conclusions are based on a limited number of samples and that further longterm studies should be carried out to investigate the effects of ENSO on integrated aspects of breeding and at additional colonies. Nevertheless, these results provide novel information on the foraging ecology of a seabird in the Eastern Tropical Pacific, which appears to be unaffected by ENSO phases.

Acknowledgements Open Access funding provided by Projekt DEAL. We thank Abigail Ocaña Feregrino, Gloria Diane López Rivas, Cesar 
Tostado, Pamela Carolina Mora Solano, Humberto Almanza, and Diego González for participating in fieldwork. We are grateful to S. Furness English editing. We are grateful to the Armada de Mexico (SEMAR) for transportation and logistics at Clarion Island, with special thanks to Captains Severino and Rivera. We thank the three anonymous reviewers who provided thoughtful recommendations that have helped us to improve the manuscript. Miriam Lerma was granted an INAPI-CONACyT Scholarship no. 262277. The study was funded by the Research and Technology Centre (FTZ), University of Kiel, and Universidad de Guadalajara.

Data availability Tracking data are archived at Movebank (https:// www.movebank.org)

\section{Compliance with ethical standards}

Conflict of interest The authors declare that they have no competing interest.

Ethical approval Fieldwork was performed in accordance with ethical international standards for the care and use of wild animals under the supervision of Dirección General de Vida Silvestre (DGVS); research permits SGPA/DGVS/02644/15 (SHV), and SGPA/DGVS/01919/17 (JACG).

Open Access This article is licensed under a Creative Commons Attribution 4.0 International License, which permits use, sharing, adaptation, distribution and reproduction in any medium or format, as long as you give appropriate credit to the original author(s) and the source, provide a link to the Creative Commons licence, and indicate if changes were made. The images or other third party material in this article are included in the article's Creative Commons licence, unless indicated otherwise in a credit line to the material. If material is not included in the article's Creative Commons licence and your intended use is not permitted by statutory regulation or exceeds the permitted use, you will need to obtain permission directly from the copyright holder. To view a copy of this licence, visit http://creativecommons.org/licenses/by/4.0/.

\section{References}

Almanza-Rodríguez H (2019) Aves marinas de la isla Clarión, Archipiélago de Revillagigedo: fenología reproductiva y análisis espacial. Bachelor thesis, Universidad de Guadalajara, Mexico

Alonso H, Granadeiro JP, Dias MP, Catry T, Catry P (2018) Fine-scale tracking and diet information of a marine predator reveals the origin and contrasting spatial distribution of prey. Prog Oceanogr 162:1-12. https://doi.org/10.1016/j.pocean.2018.02.014

Ancona S, Calixto-Albarrán I, Drummond H (2012) Effect of El Niño on the diet of a specialist seabird, Sula nebouxii, in the warm eastern tropical Pacific. Mar Ecol Prog Ser 462:261-271. https:// doi.org/10.3354/meps09851

Anderson DJ (1989) Differential responses of boobies and other seabirds in the Galapagos to the 1986-87 El Niño- Southern Oscillation event. Mar Ecol Prog Ser 52:209-216

Au DWK, Pitman RL (1986) Seabird interaction with dolphins and tuna in the Eastern Tropical Pacific. Condor 88:304-317. https:// doi.org/10.2307/1368877

Beadell JS, Schreiber EA, Schreiber RW, Schenk GA, Doherty PF Jr (2003) Survival of brown boobies (Sula leucogaster) at Johnston atoll: a long-term study. Auk 120:811-817. https://doi. org/10.2307/4090111
Burger AE, Piatt JF (1990) Flexible time budgets in breeding common murres: buffers against variable prey abundance. Stud Avian Biol 14:71-83

Cai W, Borlace S, Lengaigne M, Van RP, Collins M, Vecchi G, Timmermann A, Santoso A, McPhaden MJ, Wu L, England M, Wang G, Guilyard E, Jin F-F (2014) Increasing frequency of extreme El Niño events due to greenhouse warming. Nat Clim Chang 5:1-6. https://doi.org/10.1038/nclimate2100

Calenge C (2006) The package 'adehabitat' for the R software: a tool for the analyses of space and habitat use by animals. Ecol Model 197:516-519. https://doi.org/10.1016/j.ecolmodel.2006.03.017

Castillo-Guerrero JA, Mellink E (2011) Occasional inter-sex differences in diet and foraging behavior of the blue-footed booby: maximizing chick rearing in a variable environment? J Ornithol 152:269-277. https://doi.org/10.1007/s10336-010-0575-z

Castillo-Guerrero JA, Lerma M, Mellink E, Suazo-Guillén E, Peñaloza-Padilla EA (2016) Environmentally-mediated flexible foraging strategies in brown boobies in the Gulf of California. Ardea 104:33-47. https://doi.org/10.5253/arde.v104i1.a3

Chagnon C, Thiel M, Antunes J, Ferreira JL, Sobral P, Ory NC (2018) Plastic ingestion and trophic transfer between Easter Island flying fish (Cheilopogon rapanouiensis) and yellowfin tuna (Thunnus albacares) from Rapa Nui (Easter Island). Environ Pollut 243:127-133. https://doi.org/10.1016/j.envpol.2018.08.042

Champagnon J, Lebreton J-R, Drummond H, Anderson DJ (2018) Pacific Decadal and El Niño oscillations shape survival of a seabird. Ecology 95:1063-1072. https://doi.org/10.1002/ecy.2179

Churnside JH, Wells RJD, Boswell KM, Quinlan JA, Marchbanks RD, McCarty BJ, Sutton TT (2017) Surveying the distribution and abundance of flying fishes and other epipelagic in the northern Gulf of Mexico using airborne lidar. Bull Mar Sci 93:591-609. https://doi.org/10.5343/bms.2016.1039

CONANP (2017) Programa de Manejo Parque Nacional Revillagigedo. Mexico

Croxall JP, Reid K, Prince PA (1999) Diet, provisioning and productivity responses of marine predators to differences in availability of Antarctic krill. Mar Ecol Prog Ser 177:115-131. https://doi. org/10.3354/meps177115

Croxall JP, Butchard SHM, Lascelles B, Statterfsfield AJ, Sullivan B, Symes A, Taylor P (2012) Seabird conservation status, threats and priority actions: a global assessment. Bird Conserv Int 22:1-34. https://doi.org/10.1017/S0959270912000020

Cox SL, Miller PI, Embling CB, Scales KL, Bicknell AWJ, Hosegood PJ, Morgan G, Ingram SN, Votier SC (2016) Seabird diving behaviour reveals the functional significance of shelf-sea fronts as foraging hotspots. R Soc Open Sci. https://doi.org/10.1098/ rsos. 160317

Davenport J (1994) How and why do flying fish fly? Rev Fish Biol Fish 4:184-214

DiLorenzo E, Miller A (2017) Forecasting ENSO impacts in the california current system. OCB News 10:41

Dingle H, Drake VA (2007) What is migration? Bioscience 57:113121. https://doi.org/10.1641/B570206

DOF (2017) Decreto por el que se declara como área natural protegida, con el carácter de parque nacional, la región conocida como Revillagigedo, localizada en el Pacífico Mexicano - Diario Oficial de la Federación 27/11/2017

Dorward DF (1962) Comparative biology of the white booby and the brown booby Sula spp. at Ascension. Ibis 103:174-220. https:// doi.org/10.1111/j.1474-919X.1962.tb07244.x

Doubleday ZA, Connell SD (2018) Weedy futures: can we benefit from the species that thrive in the marine Anthropocene? Front Ecol Env. https://doi.org/10.1002/fee.1973

Drent R, Daan S (1980) The prudent parent: energetic adjustment in avian breeding. Ardea 55:225-252. https://doi.org/10.5253/arde. v68.p225 
Elliott KH, Woo K, Gaston AJ, Benvenuti S, Davoren GK (2008) Seabird foraging behaviour indicates prey type. Mar Ecol Prog Ser 354:289-303. https://doi.org/10.3354/meps07221

Fischer W, Krupp F, Schneider W, Sommer C, Carpenter KE, Niem VH (1995) Guía FAO para la identificación de especies para los fines de la pesca. Pacifico, centro-oriental. FAO. Roma.

Frölicher TL, Laufkötter C (2018) Emerging risks from marine heat waves. Nat Commun 9:650. https://doi.org/10.1038/s41467-01803163-6

Garriga J, Palmer JRB, Oltra A, Bartumeus F (2016) Expectationmaximization binary clustering for behavioural annotation. PLoS One 11:1-12. https://doi.org/10.1371/journal.pone.0151984

Gilmour ME, Castillo-Guerrero JA, Fleishman AB, HernándezVázquez S, Young HS, Shaffer SA (2018) Plasticity of foraging behaviors in response to diverse environmental conditions. Ecosphere 9:e02301. https://doi.org/10.1002/ecs2.2301

Grémillet D, Boulinier T (2009) Spatial ecology and conservation of seabirds facing global climate change: a review. Mar Ecol Prog Ser 391:121-137. https://doi.org/10.3354/meps08212

Harding A, Piatt JF, Schmutz JA, Shultz MT, Van Pelt TI, Pelt V, Kettle AB, Speckman SG (2007) Prey density and the behavioural flexibility of a marine predator: the common murre (Uria aalgae). Ecology 88:2024-2033. https://doi.org/10.1890/06-1695.1

Hijmans RJ (2019) geosphere: Spherical Trigonometry. R version 1.5-10 https://cran.r-project.org/web/packages/geosphere/

Hoegh-Guldberg O, Bruno JF (2010) The impact of climate change on the world's marine ecosystems. Science 328:1523-1528. https:// doi.org/10.1126/science.1189930

Ishikawa K, Watanuki Y (2002) Sex and individual differences in foraging behavior of Japanese cormorants in years of different prey availability. J Ethol 20:49-54. https://doi.org/10.1007/s1016 4-002-0053-z

Jenouvrier S (2013) Impacts of climate change on avian populations. Glob Chang Biol 19:1-68. https://doi.org/10.1111/gcb.12195

Kappes MA, Shaffer SA, Tremblay Y, Foley DG, Palacios DG, Robinson PW (2010) Hawaiian albatrosses track inter-annual variability in marine habitats in the North Pacific. Progr Ocean 86:246-260

Kappes MA, Weimerskirch H, Pinaud D, Le Corre M (2011) Variability of resource partitioning in sympatric tropical boobies. Mar Ecol Prog Ser 441:281-294. https://doi.org/10.3354/meps09376

Kohno H, Mizutani A, Yoda K, Yamamoto T (2019) Movements and activity characteristics of the brown booby Sula leucogaster during the non-breeding period. Mar Ornithol 47:167-174

Kokubun N, Takahashi A, Mori Y, Watabane S, Shin HC (2010) Comparison of diving behavior and foraging habitat use between chinstrap and Gentoo penguins breeding in the South Shetland Islands, Antarctica. Mar Biol 157:811-825. https://doi.org/10.1007/s0022 7-009-1364-1

Lacerda L, Goyanna F, Silva G (2017) Mercury concentrations in tuna (Thunnus albacares and Thunnus obesus) from the Brazilian Equatorial Atlantic Ocean. Bull Environ Contam Toxicol 98:149-155. https://doi.org/10.1007/s00128-016-2007-0

Lascelles B, Taylor PR, Miller MGR, Dias MP, Oppel S, Torres L, Hedd A, Le Corre M, Phillips RA, Scott SA, Weimerskirch $\mathrm{H}$, Small C (2016) Applying global criteria to tracking data to define important areas for marine conservation. Diversity Distrib 22:422-431. https://doi.org/10.1111/ddi.12411

Lewallen EA, Van Wijnen AJ, Bonin CA, Lovejoy NR (2018) Flyingfish (Exocoetidae) species diversity and habitats in the eastern tropical Pacific Ocean. Mar Biodivers 48:1755-1765. https://doi. org/10.1007/s12526-017-0666-7

Lluch-Belda D, Lluch-Cota DB, Lluch-Cota SE, Ramírez-Rodríguez M, Salinas-Zavala C (2014) Fisheries of Northwest Mexico. In: Wehncke E V, Lara-Lara JR, Álvarez-Borrego S, Ezcurra E (eds) Conservation science in Mexico's Northwest ecosystem status and trends in the Gulf of California, Mexico. https://doi.org/10.13140 /RG.2.1.5136.1047

Lluch-Cota SE (2000) Coastal upwelling in the eastern Gulf of California. Oceanol Acta 23:731-740. https://doi.org/10.1016/S0399 $-1784(00) 00121-3$

Machovsky-Capuska GE, Vaughn RL, Würsig B, Katzir G, Raubenheimer D (2011) Dive strategies and foraging effort in the Australasian gannet Morus serrator revealed by underwater videography. Mar Ecol Prog Ser 442:255-261. https://doi.org/10.3354/meps0 9458

McPhaden MJ, Zebiak SE, Glantz MH (2006) ENSO as integrating concept in Earth science. Science 314:1740-1745. https://doi. org/10.1126/science. 1132588

Mellink E (2003) Effects if the 1997-1998 El Niño and 1998-1999 La Niña events on breeding waterbirds and sea lions in the Upper Gulf of California, Mexico. Geofis Int 42:539-546

Mendez L, Borsa P, Cruz S, De Grissac S, Hennicke J, Lallemand J, Prudor A, Weimerskirch H (2017) Geographical variation in the foraging behaviour of the pantropical red-footed booby. Mar Ecol Prog Ser 568:217-230. https://doi.org/10.3354/meps12052

Miller MGR, Silva FRO, Machovsky Capuska GE, Congdon BC (2018) Sexual segregation in tropical seabirds: drivers of sex-specific foraging in the Brown Booby Sula leucogaster. J Ornithol 159:425437. https://doi.org/10.1007/s10336-017-1512-1

Monahan WB, Fisichelli NA (2014) Climate exposure of US national parks in a new era of change. PLoS ONE 9:e101302. https://doi. org/10.1371/journal.pone.0101302

Muramatsu K, Yamamoto J, Abe T, Sekiguchi K, Hoshi N, Sakurai Y (2013) Oceanic squid do fly. Mar Biol 160:117-1175. https://doi. org/10.1007/s00227-013-2169-9

Nelson JB (1978) The Sulidae: gannets and boobies. Oxford University Press, Oxford

Newton I (2012) Obligate and facultative migration in birds: ecological aspects. J Ornithol 153:171-180. https://doi.org/10.1007/s1033 6-011-0765-3

Oksanen J (2019) Vegan: community ecology package. R version 2.5-5. https://cran.r-project.org/web/packages/vegan/

Oppel S, Beard A, Fox D, Mackley E, Leat E, Henry L, Clingham E, Fowler N, Sim J, Sommerfeld J, Weber N, Weber S, Bolton M (2015) Foraging distribution of a tropical seabird supports Ashmole's hypothesis of population regulation. Behav Ecol Sociobiol 69:915-926. https://doi.org/10.1007/s00265-015-1903-3

Oro D (2014) Seabirds and climate: knowledge, pitfalls, and opportunities. Front Ecol Evol 2:1-12. https://doi.org/10.3389/ fevo.2014.00079

Oro D, Torres R, Rodríguez C, Drummond H (2010) Climatic influence on demographic parameters of a tropical seabird varies with age and sex. Ecology 91:1205-1214. https://doi. org/10.1890/09-0939.1

Oro D, Álvarez D, Velando A (2018) Complex demographic heterogeneity from anthropogenic impacts in a coastal marine predator. Ecol Appl 28:612-621. https://doi.org/10.1002/eap.1679

Paiva VH, Geraldes P, Ramirez I, Meirinho A, Garthe S, Ramos JA (2010) Foraging plasticity in a pelagic seabird species along a marine productivity gradient. Mar Ecol Prog Ser 398:259-274. https://doi.org/10.3354/meps08319

Paiva VH, Pereira J, Ceia FR, Ramos JA (2017) Environmental driven sexual segregation in a marine top predator. Sci Rep 7:2590. https ://doi.org/10.1038/s41598-017-02854-2

Patrick SC, Weimerskirch H (2014) Consistency pays: sex differences and fitness consequences of behavioural specialization in a wideranging seabird. Biol Lett 10:20140630. https://doi.org/10.1098/ rsbl.2014.0630

Peck-Richardson AG, Lyons DE, Roby DD, Cushing DA, Lerczak JA (2018) Three-dimensional foraging habitat use and niche 
partitioning in two sympatric seabird species, Phalacrocorax auritus and P. penicillatus. Mar Ecol Prog Ser 586:251-264. https:// doi.org/10.3354/meps 12407

Pinheiro J, Bates D, DebRoy S, Sarkar D, R Core Team (2019) Package 'nlme'. https://cran.r-project.org/package $=$ nlme

Poli CL, Harrison A-L, Vallarino A, Gerard PD, Jodice PGR (2017) Dynamic oceanography determines fine scale foraging behavior of masked boobies in the Gulf of Mexico. PLoS ONE 12:e0179318. https://doi.org/10.1371/journal.pone.0178318

Priddel D, Hutton I, Olson S, Wheeler R (2005) Breeding biology of masked boobies (Sula dactylatra tasmani) on Lord Howe Island, Australia. Emu 105:105-113. https://doi.org/10.1071/MU04028

QGIS Development Team (2019) QGIS Geographic Information System. Open Source Geospatial Foundation Project

Quillfeldt P, Masello JF (2013) Impacts of climate variation and potential effects of climate change on South American seabirds: a review. Mar Biol Res 9:337-357. https://doi.org/10.1080/17451 000.2012 .756982

Core Team R (2019) R: a language and environment for statistical computing. R Foundation for Statistical Computing, Vienna

Ribic CA, Ainley DG, Spear LB (1997) Scale-related seabird-environmental relationships in Pacific equatorial waters, with reference to El Niño-Southern oscillation events. Mar Ecol Prog Ser 156:183-203. https://doi.org/10.3354/meps 156183

Schreiber RW, Hensley DA (1976) The diets of Sula dactylatra, Sula sula, and Fregata minor on Christmas Island, Pacific Ocean. Pacific Sci 30:241-248

Schreiber EA, Schreiber RW (1989) Insights into seabird ecology from a global 'natural experiment'. Nat Geo Res 5:64-79

Smale DA, Wernberg T, Oliver ECJ, Thomsen M, Harvey BP, Straub SC, Burrows MT, Alexander LV, Benthuysen JA, Donat MG, Feng M, Hobday AJ, Holbrook NJ, Perkins-Kirkpatrick SE, Scannell HA, Sen GA, Payne BL, Moore PJ (2019) Marine heatwaves threaten global biodiversity and the provision of ecosystem services. Nat Clim Change 9:306-312. https://doi.org/10.1038/s4155 8-019-0412-1

Sommerfeld J, Kato A, Ropert-Coudert Y, Garthe S, Hindell MA (2013) The individual counts: within sex differences in foraging strategies are as important as sex-specific differences in masked boobies Sula dactylatra. J Avian Biol 44:531-540. https://doi. org/10.1111/j.1600-048X.2013.00135.X

Sommerfeld J, Kato A, Ropert-Coudert Y, Garthe S, Wilcox C, Hindell MA (2015) Flexible foraging behaviour in a marine predator the masked booby (Sula dactylatra), according to foraging locations and environmental conditions. J Exp Mar Bio Ecol 463:79-86. https://doi.org/10.1016/j.jembe.2014.11.005

Spear LB, Ballance LT, Ainley DG (2001) Response of seabirds to thermal boundaries in the tropical Pacific: the thermocline versus the equatorial front. Mar Ecol Prog Ser 219:275-289. https://doi. org/10.3354/meps 219275
Tompkins EM, Townsend HM, Anderson DJ (2017) Decadal-scale variation in diet forecast persistently poor breeding under ocean warming in a tropical seabird. PLoS ONE 12:e0182545. https:// doi.org/10.1371/journal.pone.0182545

Trenberth KE, Hoar TJ (1997) El Niño and climate change. Geophys Res Lett 24:3057-3060. https://doi.org/10.1029/97GL03092

Valencia-Gasti JA, Baumgartner T, Durazo R (2015) Effects of ocean climate on life cycles and distribution of small pelagic fishes in the California Current System off Baja California. Ciencias Mar 41:315-348.

Vandenabeele SP, Shepard EL, Grogan A, Wilson RP (2012) When three per cent may not be three per cent; device-equipped seabirds experience variable flight constraints. Mar Biol 159:1-14. https:// doi.org/10.1007/s00227-011-1784-6

Vargas FH, Harrison S, Rea S, Macdonald DW (2006) Biological effects of El Niño on Galapagos penguin. Biol Conserv 127:107114. https://doi.org/10.1016/j.biocon.2005.08.001

Velarde E, Ezcurra E, Cisneros-Mata MA, Lavín M (2004) Seabird ecology, El Niño anomalies, and prediction of sardine fisheries in the Gulf of California. Ecol Appl 14:607-615. https://doi. org/10.1890/02-5320

Walther G-R, Post E, Convey P, Menzel A, Parmesan C, Beebee TJC, Fromentin J-M, Hoegh-Guldberg O, Bairlein F (2002) Ecological responses to recent climate change. Nature 416:389-395. https:// doi.org/10.1038/416389a

Wanless RM, Aguirre-Muñoz A, Angel A, Jacobsen JK, Keitt BS, McCann J (2009) Birds of Clarion Island, Revillagigedo Archipelago, Mexico. Wilson J Ornithol 121:745-751. https://doi. org/10.1676/08-140.1

Weimerskirch H, Le Corre M, Gadenne H, Pinaud D, Kato A, Ropert-Coudert Y, Bost CA (2009) Relationship between reversed sexual dimorphism, breeding investment and foraging ecology in a pelagic seabird, the masked booby. Oecologia 161:637-649. https://doi.org/10.1007/s00442-009-1397-7

Wilson RP, McMahon CR (2006) Measuring devices on wild animals: what constitutes acceptable practice? Front Ecol Environ 4:147154. https://doi.org/10.1890/1540-9295(2006)004[0147:MDOWA $\mathrm{W}] 2.0 . \mathrm{CO} ; 2$

Wingfield JC, Hau M, Boersma PD, Romero LM, Hillgarth N (2018) Effects of El Niño and La Niña Southern Oscillation events on the adrenocortical responses to stress in birds of the Galapagos Islands. Gen Comp Endocrinol 259:20-33. https://doi. org/10.1016/j.ygcen.2017.10.015

Young HS, Shaffer SA, McCauley DJ, Foley DG, Dirzo R, Block BA (2010) Resource partitioning by species but not sex in sympatric boobies in the central Pacific Ocean. Mar Ecol Prog Ser 403:291301. https://doi.org/10.3354/meps08478

Publisher's Note Springer Nature remains neutral with regard to jurisdictional claims in published maps and institutional affiliations. 